\title{
Overt Congestive Heart Failure with Mitral and Aortic Regurgitation due to Antiphospholipid Syndrome in a Patient with Systemic Lupus Erythematosus
}

\author{
Hiroyuki Morita, Hisashi Daido*, Tetsuya SuwA*, Tomoatsu Mune*, Koji Yoshino*, Yukinori Isomura*, \\ Tetsuya TANAHASH* ${ }^{*}$, Noriyuki TAKedA*, Tatsuo IshizUKA and Keigo YasudA*
}

\begin{abstract}
A 51-year-old woman with overt congestive heart failure with pleural and pericardial effusion was treated with furosemide and nifedipine, leading to improvement in her condition and a decrease in effusions. An echocardiography demonstrated mitral and aortic regurgitation with mitral valve prolapse, which caused the congestive heart failure. Since leukocytopenia and lymphocytopenia with arthralgia could be observed, serological investigations were performed. She was diagnosed as having systemic lupus erythematosus (SLE) with antiphospholipid syndrome, and started on a treatment of prednisolone and aspirin. Based on the treatment, the pleural and pericardial effusion went into complete remission, indicating that the serositis related to SLE had overlapped the heart failure. Since there was no evidence of any other diseases that could be responsible for the valvular lesions, we concluded that they were due to antiphospholipid syndrome. The administration of prednisolone had no significant effect on valvular morphology or function as demonstrated by echocardiography. When patients with valvular disease are seen, a valvulopathy related to antiphospholipid syndrome should be considered as part of the differential diagnosis. (Internal Medicine 39: 506-511, 2000)
\end{abstract}

Key words: SLE, anti-cardiolipin- $\beta_{2}$-glycoprotein I antibody, pericarditis, endocarditis, valvulopathy

\section{Introduction}

Antiphospholipid syndrome is characterized by the clinical evidence of arterial or venous thrombosis, recurrent fetal loss, and thrombocytopenia accompanied by an elevated level of at least one of the antiphospholipid antibodies (1). The syndrome is either primary or secondary to an underlying condition, most commonly systemic lupus erythematosus (SLE) (2). The spectrum of clinical manifestations appearing in patients with antiphospholipid syndrome is wide and diverse, including neurological disorders such as chorea and cutaneous features such as livedo reticularis (1). Valvular abnormalities have also become more recognized as one of the important features of this syndrome, although such abnormalities are clinically silent in most of the cases (1,3-9). We report a case of systemic lupus erythematosus with overt congestive heart failure due to mitral and aortic regurgitation, which was caused by antiphospholipid syndrome.

For editorial comment, see p 446.

\section{Case Report}

A 51-year-old woman was admitted to Gifu University Hospital in November 1995 with orthopnea. She had two miscarriages at the ages of 22 and 24 during the 3rd and 4th gestational months, respectively, and was unable to bear a child. Her skin had been mildly photosensitive for ten years. She had no history of rheumatic fever and had been well until 1993, when she began to suffer from multiple arthralgia. Two months before the current admission, she had begun to experience nocturnal dyspnea and chest discomfort. She was diagnosed as having congestive heart failure due to valvular disease by a private doctor and was referred to our hospital.

On admission, she was $1.49 \mathrm{~m}$ tall and weighed $44.4 \mathrm{~kg}$. Her temperature was $37.8^{\circ} \mathrm{C}$, the pulse was $88 / \mathrm{min}$, and respiration was $18 / \mathrm{min}$. Her blood pressure was $178 / 102 \mathrm{mmHg}$. Further stethoscope examination revealed fine crackles at both lung bases, and a grade 3 holosystolic murmur was transmitted from the apex to the axilla. No erythema of skin, mucosal lesions or lymphadenopathy was detected, except for some pigmentation of the cheek. A sharp liver edge $5 \mathrm{~cm}$ below the

From the Department of General Medicine and *the Third Department of Internal Medicine, Gifu University School of Medicine, Gifu

Received for publication July 5, 1999; Accepted for publication November 19, 1999

Reprint requests should be addressed to Dr. Hiroyuki Morita, the Department of General Medicine, Gifu University School of Medicine, 40 Tsukasa, Gifu 5008705 
right costal margin was palpated. Pretibial pitting edema could be observed. An electrocardiogram demonstrated sinus rhythm at a rate of 96 and left ventricular hyperplasia with ST depression at $\mathrm{I},{ }_{\mathrm{a}} \mathrm{V}_{\mathrm{L}}, \mathrm{V}_{5}$ and $\mathrm{V}_{6}$. A radiograph of the chest demonstrated bilateral pleural effusions and pulmonary edema with marked cardiac enlargement (Fig. 1A). A two-dimensional and Doppler echocardiography revealed moderate mitral regurgitation with mild prolapse of the anterior mitral leaflet, dilatation of the left atrium and a moderate volume of pericardial effusion (Fig. 2). No vegetation or calcification on the valves could be observed. Papillary muscles and chordae tendineae were intact. The diameter of the mitral annulus was normal. Mild aortic regurgitation without calcification on the valve leaflets was also detected. Left ventricular systolic function was diffusely reduced. No echocardiographic sign suggesting pulmonary hypertension was seen. Blood cultures were sterile. Puncture of pleural or pericardial effusion was not performed. She was diagnosed as having congestive heart failure (New York Heart Association functional class III) mainly due to mitral regurgitation. Furosemide $(40 \mathrm{mg} /$ day) and nifedipine (40 $\mathrm{mg}$ /day) were administered. Continuous administration led to improvements in left ventricular function and pericardial and pleural effusions (Fig. 1B), but a small amount of effusion could still be observed. Angiography, performed a month after admission, demonstrated no significant stenosis of the coronary arteries and Sellers grade 2 mitral regurgitation, suggesting no indication of valve replacement.

Urinary protein excretion was $350 \mathrm{mg} /$ day and no urinary cast was observed. Creatinine clearance was $42 \mathrm{ml} / \mathrm{min}$. A renal biopsy was not performed. Occult blood in the feces was positive. Results of other laboratory tests are shown in Tables 1 and 2. Hemoglobin concentration was normalized to $13.6 \mathrm{~g} /$ dl by a daily oral supplement of iron for 4 months. Based on the results of a gastric and colon endoscopy, a duodenal ulcer scar was considered to have been the cause of gastrointestinal bleeding. The elevated serum alkaline phosphatase level was normalized through the treatments for the congestive heart failure, suggesting that it may have been induced by hepatic congestion. There was no evidence to indicate autoimmune hepatitis based on our laboratory tests (Table 2).

Leukocytopenia, lymphocytopenia and low serum complements could be observed. Double-strand anti-DNA antibody and antinuclear antibody were positive. Together with the physical findings, she was diagnosed as having SLE based on the criteria of the American College of Rheumatology, which was revised in 1997 (10). Based on our laboratory findings, her disease was considered to be active. Although platelet counts were normal and a venereal disease research laboratory test for syphilis was negative, prothrombin and partial thromboplastin time were prolonged. Lupus anticoagulant via diluted antiprothrombin time and anti-cardiolipin- $\beta_{2}$-glycoprotein I antibody via enzyme-linked immunosorbent assay were positive. Existence of these antibodies in the serum was verified 6 months later. These findings, including the history of miscarriages, met the criteria for antiphospholipid syndrome (1).

Prednisolone (30 mg/day) and aspirin $(81 \mathrm{mg} /$ day) were additionally administered for treatment of the SLE and prevention of thromboses associated with antiphospholipid syndrome, respectively. As a result, improvements were seen in her arthralgia, and her fever decreased. The pleural and pericardial effusion almost completely disappeared (Fig. 1C), suggesting that the pericarditis and pleuritis related to SLE had overlapped the congestive heart failure. Her prednisolone dosage was gradually reduced, and finally, alternative-day prednisolone treatment (15 mg/every other day) and aspirin (81 $\mathrm{mg} /$ day) have been continued to maintain clinical remission

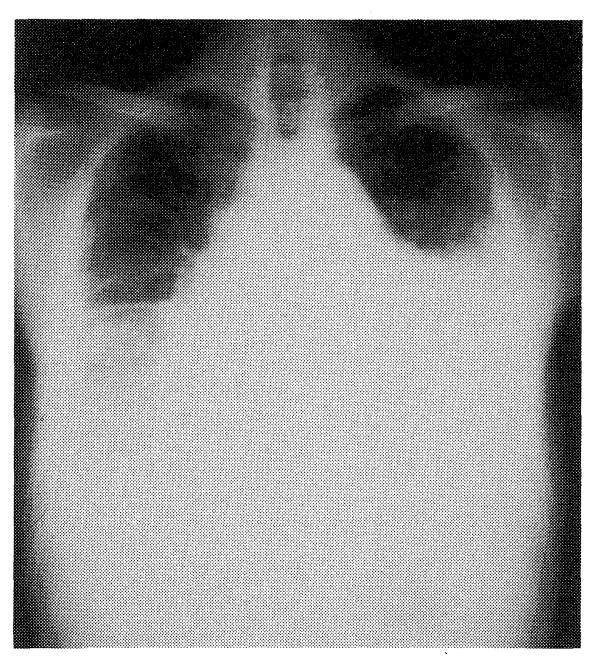

A

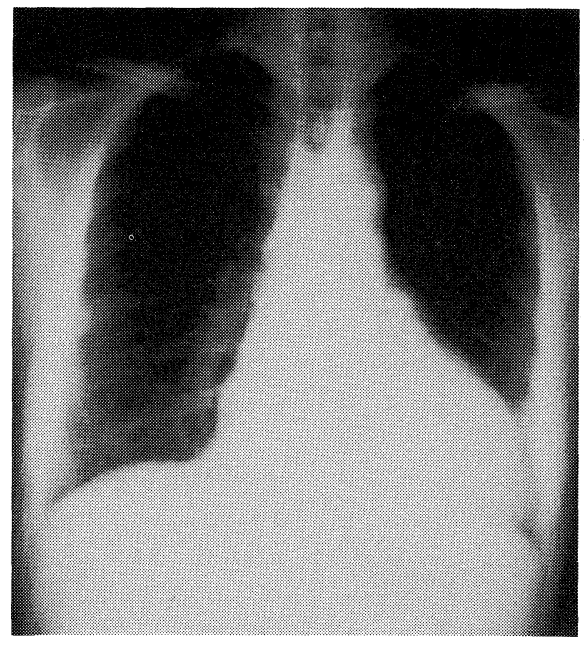

B

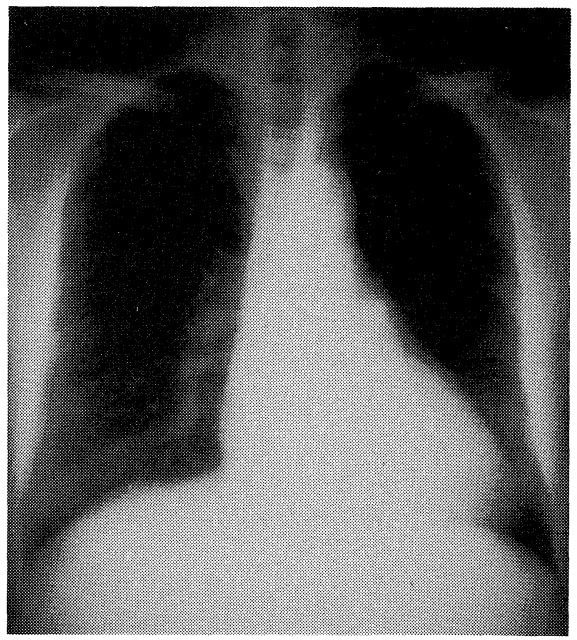

$\mathrm{C}$

Figure 1. Chest roentgenogram on admission (A), after treatment with furosemide and nifedipine (B) and after prednisolone administration. 


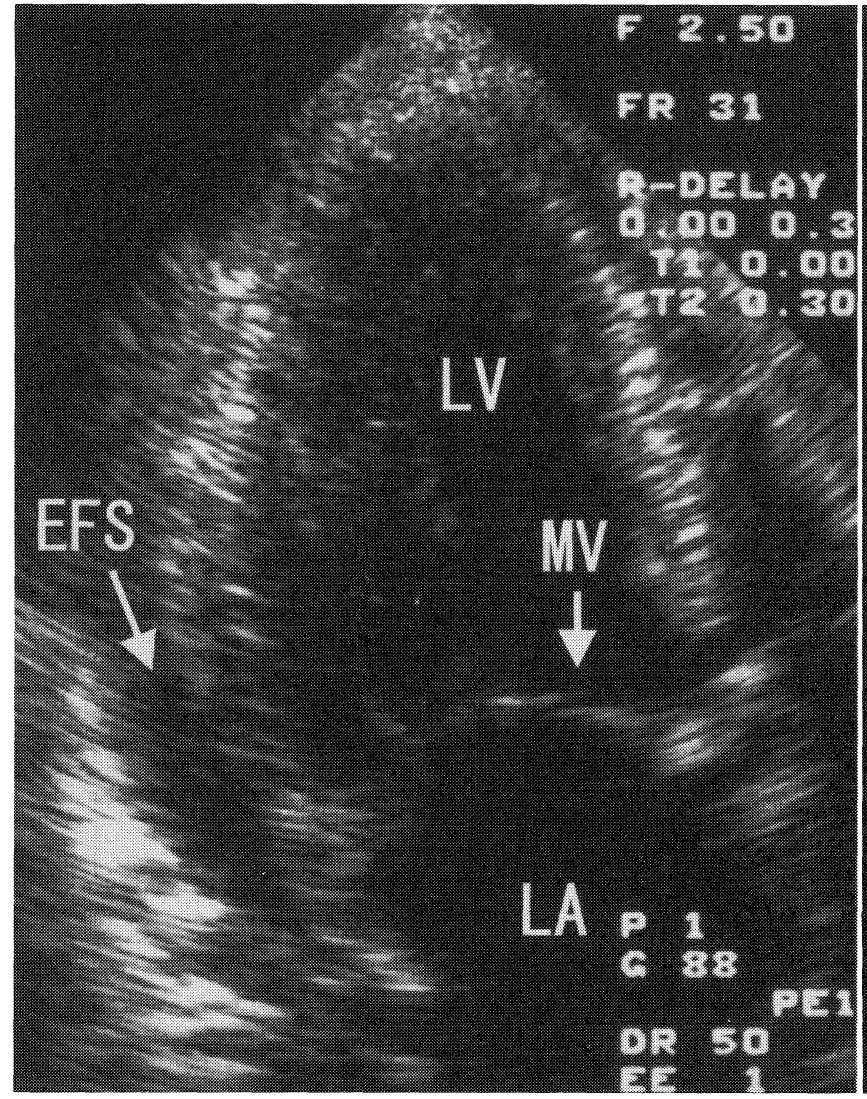

A

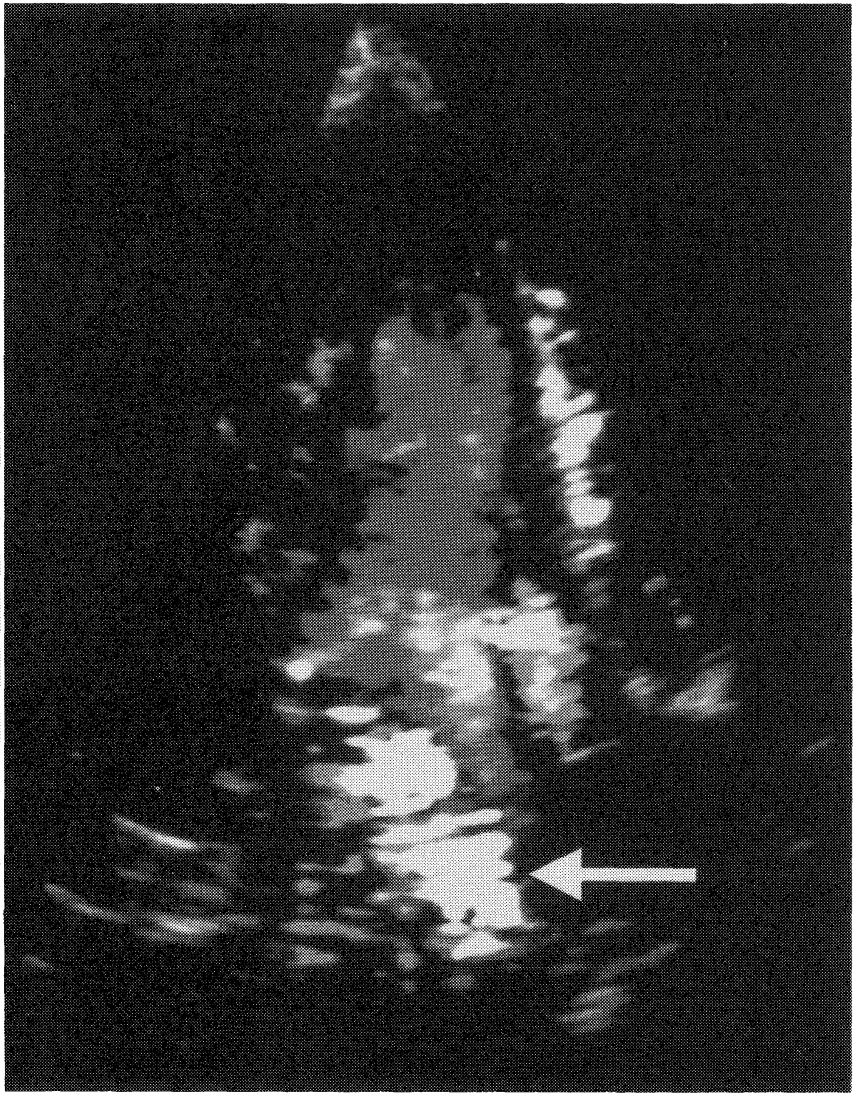

B

Figure 2. Two-dimensional (A) and its Doppler (B) echocardiogram on admission showed pericardial effusion (EFS), dilatation of the left atrium (LA) and mild wall thickness of the left ventricle (LV), and mitral valve (MV) regurgitation, indicated with a broad arrow in $B$.

Table 1. Laboratory Data on Admission (1)

\begin{tabular}{|c|c|c|c|}
\hline \multicolumn{2}{|l|}{ Peripheral blood } & Erythrocyte sedimentation rate & $133 \mathrm{~mm} / \mathrm{h}$ \\
\hline White blood cells & $3,300 / \mu 1$ & Blood chemistry & \\
\hline Neutrophil & $57 \%$ & Sodium & $138 \mathrm{mEq} / \mathrm{l}$ \\
\hline Eosinophil & $5 \%$ & Potassium & $3.9 \mathrm{mEq} / \mathrm{l}$ \\
\hline Basophil & $1 \%$ & Chloride & $101 \mathrm{mEq} / \mathrm{l}$ \\
\hline Monocyte & $8 \%$ & Blood urea nitrogen & $19.5 \mathrm{mg} / \mathrm{dl}$ \\
\hline Lymphocyte & $26 \%$ & Creatinine & $1.4 \mathrm{mg} / \mathrm{dl}$ \\
\hline Red blood cells & $3.63 \times 10^{6} / \mu 1$ & Uric acid & $5.9 \mathrm{mg} / \mathrm{dl}$ \\
\hline Hematocrit & $25.1 \%$ & Calcium & $4.4 \mathrm{mEq} / \mathrm{l}$ \\
\hline Hemoglobin & $7.5 \mathrm{~g} / \mathrm{dl}$ & Total protein & $8.8 \mathrm{~g} / \mathrm{dl}$ \\
\hline Platelet & $351 \times 10^{3} / \mu 1$ & Albumin & $3.2 \mathrm{~g} / \mathrm{dl}$ \\
\hline Reticulocytes & $1.5 \%$ & Total bilirubin & $0.3 \mathrm{mg} / \mathrm{dl}$ \\
\hline Coagulation tests & & Aspartate aminotransferase & $20 \mathrm{IU} / l$ \\
\hline Prothrombin time & $25 \%$ & Alanine aminotransferase & $18 \mathrm{IU} / l$ \\
\hline Activated partial thromboplastin time & $62.1 \mathrm{~s}$ & Lactate dehydrogenase & $345 \mathrm{IU} / l$ \\
\hline Fibrinogen & $365 \mathrm{mg} / \mathrm{dl}$ & Alkaline phosphatase & $570 \mathrm{IU} / l$ \\
\hline Fibrinogen degradation product & $234 \mathrm{ng} / \mathrm{ml}$ & Gamma-glutamyl transpeptidase & $61 \mathrm{IU} / \mathrm{l}$ \\
\hline Arterial blood gas analysis in room air & & Choline esterase & $262 \mathrm{IU} / l$ \\
\hline $\mathrm{pH}$ & 7.35 & Creatinine kinase & $36 \mathrm{IU} / l$ \\
\hline $\mathrm{PaCO}_{2}$ & $38.8 \mathrm{mmHg}$ & Iron & $15 \mu \mathrm{g} / \mathrm{dl}$ \\
\hline $\mathrm{PaO}_{2}$ & $64.9 \mathrm{mmHg}$ & Unsaturated iron binding capacity & $456 \mu \mathrm{g} / \mathrm{dl}$ \\
\hline $\mathrm{HCO}_{3}^{-}$ & $21 \mathrm{mmol} / \mathrm{l}$ & Haptoglobin & $246 \mathrm{mg} / \mathrm{dl}$ \\
\hline
\end{tabular}


Mitral Regurgitation due to Antiphospholipid Syndrome

Table 2. Laboratory Data on Admission (2)

\begin{tabular}{lrr}
\hline & & (normal range) \\
Venereal disease research laboratory test & $(-)$ & $(-)$ \\
C-reactive protein & $2.3 \mathrm{mg} / \mathrm{dl}$ & $(<0.4)$ \\
Immunoglobulin G & $3,781 \mathrm{mg} / \mathrm{dl}$ & $(1,000-1,650)$ \\
Immunoglobulin A & $497 \mathrm{mg} / \mathrm{dl}$ & $(150-300)$ \\
Immunoglobulin M & $441 \mathrm{mg} / \mathrm{dl}$ & $(70-170)$ \\
$\mathrm{CH}_{50}$ & $42 \mathrm{IU} / \mathrm{ml}$ & $(30-40)$ \\
Third component of complement & $63.1 \mathrm{mg} / \mathrm{dl}$ & $(60-100)$ \\
Forth component of complement & $26 \mathrm{mg} / \mathrm{dl}$ & $(20-50)$ \\
Anti-nuclear antibody & $1: 1,280, \mathrm{Speckled}$ & $(<1: 20)$ \\
Rheumatoid factor & $19.8 \mathrm{IU} / \mathrm{ml}$ & $(<10)$ \\
Anti-double strand DNA antibody & $491 \mathrm{IU} / \mathrm{ml}$ & $(12-20)$ \\
Anti-single strand DNA antibody & $189 \mathrm{AU} / \mathrm{ml}$ & $(25-40)$ \\
Anti-ribonuclear protein antibody & $(+)$ & $(-)$ \\
Anti-Sm antibody & $( \pm)$ & $(-)$ \\
Lupus anticoagulant & $(+)$ & $(-)$ \\
Anti-cardiolipin $\bullet \beta_{2}$-glycoprotein I antibody & $21.8 \mathrm{U} / \mathrm{ml}$ & $(<3.5)$ \\
Anti-cardiolipin IgG antibody & 1.2 & $(<1)$ \\
Anti-mitochondrial antibody & $<1: 20$ & $(<1: 20)$ \\
Anti-smooth muscle antibody & $<1: 20$ & $(<1: 20)$ \\
\hline
\end{tabular}

for the past 3 years. No significant change in the mitral and aortic valves and their regurgitation was observed in a 3-year follow-up study. Reduced renal function and proteinuria have not improved even after the prednisolone treatment.

\section{Discussion}

The characteristic endocardial lesions related to SLE have been described by Libman and Sacks, consisting of wartlike lesions most often located at the angles of the aortic valves or on the ventricular surface of the mitral valve. Noninfective verrucous vegetations (Libman-Sacks endocarditis) have been present in up to 50\% of patients with SLE at necropsy (11). However, documentation of such lesions during life has been rare (4). The introduction of two-dimensional and Doppler echocardiography has aided in revealing the high prevalence of verrucous vegetations and other valvular abnormalities in SLE patients. In a prospective study of SLE patients, the probability of developing valvulopathy appears to increase with higher levels of antiphospholipid antibodies (6). Another prospective study has demonstrated an association between antibodies against phospholipids and heart valvular lesions (4). The incidence of valvular lesions in patients with SLE has been found to be $23 \%$ compared with $3 \%$ in healthy volunteers. The prevalence of valve vegetations (16\%) and of mitral regurgitation $(38 \%)$ is significantly higher among SLE patients with antiphospholipid antibodies than among those without (1.2\% and $12 \%$, respectively). Other prospective studies have also demonstrated that the prevalence of valvular lesions is significantly higher in the former than in the latter $(8,12,13)$. However, in one study using trans-esophageal echocardiography, which is more sensitive than ordinary echocardiography, val- vular involvement has been found to be common in both antiphospholipid antibody-positive and -negative SLE patients and the degree of incidence does not differ (77\% vs. $72 \%$ ) (14). In patients with primary antiphospholipid syndrome, a higher prevalence (32-38\%) of significant heart valve involvement can be observed than in control subjects $(0-5 \%)(7,15,16)$. Furthermore, several studies have found no association between valvular disease and indicators of the activity of $\operatorname{SLE}(14,17)$. These clinical studies suggest a significant link between heart valve lesions and antiphospholipid antibodies, not SLE.

Thickening of valve leaflets is morphologically the most common lesion, followed by valvular vegetations or mitral valve prolapse $(4,8)$. The predominant functional abnormality is regurgitation, and stenosis is rare. The mitral valve is mainly involved, followed by the aortic valve. Valvular lesions in the present case are concordant with these characteristics except for the lack of thickness of the valves or valvular vegetations.

The etiology of valvular lesions other than antiphospholipid syndrome in the present case can be safely denied because of the echocardiographic findings, no dilatation of the mitral annulus, no elongation or rupture of chordae tendineae and normal function of papillary muscles. Morphological characteristics of valvular lesions in patients with rheumatic fever include leaflet thickening on the edge, leaflet calcification and chordal thickening. In contrast, in antiphospholipid syndrome, leaflet thickening is diffuse, and leaflet calcification and chordal thickening are rare or minimal (9). These findings suggest that, in the present case, deformity of the valve leaflets and mitral valve prolapse related to antiphospholipid syndrome are responsible for the mitral and aortic regurgitation.

Nevertheless, most valvular lesions are clinically silent and can only be detected by echocardiography or chest ausculta- 
tion (3-9). Only 4 to $6 \%$ of patients with SLE and primary antiphospholipid syndrome develop severe mitral and aortic regurgitation, which causes congestive heart failure (9). Half of these patients require valve replacement surgery. The present case was a typical case presenting overt heart failure caused by valvular lesions associated with antiphospholipid syndrome and SLE.

The pathogenesis of valvular lesions has become clearer. It has been shown that subpopulations of antiphospholipid antibodies in the sera of patients with antiphospholipid syndrome bind to endothelial cells (18). This binding is directed to cellmembrane phospholipids (19) or mediated by phospholipidbinding plasma proteins, such as $\beta_{2}$-glycoprotein I, which adhere to or are expressed on the endothelial surface and induce the expression of adhesion molecules (20). In a recent immunohistochemical study, linear deposition of IgG anticardiolipin antibodies with complement components in the subendothelial layer of heart valves has been demonstrated and found to be common in patients with antiphospholipid syndrome, while it has not been observed in any of the normal or altered control valves (21). Anticardiolipin specificity of deposited antibodies has been further verified by elution of immunoglobulin from a valve of a patient with secondary antiphospholipid syndrome. These findings suggest that an immunologic injury on the valves mediated by the immune complex contribute to the pathogenesis of the valvular lesions. However, it is not known whether the subendothelial deposition of antiphospholipid syndrome was a primary event due to a specific antigen-antibody interaction or secondary to another initiating insult (8).

As mentioned before, most patients with valvular lesions exhibit no symptoms, and no special treatment is necessary. In a study in SLE patients, valvular abnormalities were frequently resolved, appeared, or persisted but with alterations in appearance or size during a follow-up period (the average was 57 months) (14). Moreover, the presence of valvular disease is not temporally related to clinical activity or severity. This study suggests that in a patient with stable lupus, newly diagnosed valvular disease may not reflect an increase in the activity of the lupus, therefore there is no need to modify anti-inflammatory therapy. On the other hand, patients with overt congestive heart failure related to valvulopathy should be treated first with diuretics and/or some vasodilators. Nesher et al has addressed the efficiency of systemic glucocorticoids ( 40 to $60 \mathrm{mg} /$ day) on symptomatic valvulopathy related to antiphospholipid syndrome (9). Rapid improvement in valve thickness and hemodynamics with a minimal effect on the level of antiphospholipid antibodies has been observed in 4 patients who were newly diagnosed. The authors suggest that the mechanism of the action of steroids is related to their anti-inflammatory effects on valve tissue. On the other hand, Shahian et al described that glucocorticoid treatment resulted in no improvement of chronic mitral regurgitation in a patient with primary antiphospholipid syndrome (22). Steroids may facilitate healing of valvular vegetations, which may result in marked scarring and deformity of the valve, thereby most likely leading to valve dysfunction (8). The present patient did not show any morphological or hemodynamic improvement in mitral and aortic regurgitation during treatment with prednisolone. It may have been too late to administer it because no thickness of the leaflets of the mitral or aortic valves could be observed, which may reflect that the inflammation had already diminished. Alternatively, the dose could have been too small to be effective (initial dose was $30 \mathrm{mg} /$ day for our patient). Nevertheless, a trial dose of steroids may be considered at least for symptomatic patients with recent-onset valvular lesions due to antiphospholipid syndrome, until a more specific treatment can be established.

Finally, all patients with SLE or antiphospholipid syndrome should be examined by echocardiography. Further, the possibility of antiphospholipid syndrome should be considered in all patients with mitral and/or aortic valvular diseases.

\section{References}

1) Asherson RA, Cervera R. Antiphospholipid syndrome. in: Textbook of Rheumatology. $5^{\text {th }}$ edition. Kelley WN, Harris ED, Ruddy S, Sledge CB, Eds. Saunders, Philadelphia, 1997: 1057-1064.

2) Vianna JL, Khamashta MA, Ordi-Ros J, et al. Comparison of the primary and secondary antiphospholipid syndrome: a European multicenter study of 114 patients. Am J Med 96: 3-9, 1994.

3) Chartash EK, Lans DM, Paget SA, Qamar T, Lockshin MD. Aortic insufficiency and mitral regurgitation in patients with systemic lupus erythematosus and the antiphospholipid syndrome. Am J Med 86: 407-412, 1989.

4) Khamashta MA, Cervera R, Asherson RA, et al. Association of antibodies against phospholipids with heart valve disease in systemic lupus erythematosus. Lancet 335: 1541-1544, 1990.

5) Leung W-H, Wong K-L, Lau C-P, Wong C-K, Liu H-W. Association between antiphospholipid antibodies and cardiac abnormalities in patients with systemic lupus erythematosus. Am J Med 89: 411-419, 1990.

6) Nihoyannopoulos P, Gomez PM, Joshi J, Loizou S, Walport MJ, Oakley CM. Cardiac abnormalities in systemic lupus erythematosus: association with raised anticardiolipin antibodies. Circulation 82: 369-375, 1990.

7) Galve E, Ordi J, Barquinero J, Evangelista A, Vilardell M, Soler-Soler J. Valvular heart disease in the primary antiphospholipid syndrome. Ann Intern Med 116: 293-298, 1992.

8) Hojnik M, George J, Ziporen L, Shoenfeld Y. Heart valve involvement (Libman-Sacks endocarditis) in the antiphospholipid syndrome. Circulation 93: 1579-1587, 1996.

9) Nesher G, Ilany J, Rosenmann D, Abraham AS. Valvular dysfunction in antiphospholipid syndrome: prevalence, clinical features, and treatment. Semin Arthritis Rheum 27: 27-35, 1997.

10) Hochberg MC. Updating the American College of Rheumatology Revised Criteria for the Classification of Systemic Lupus Erythematosus. Arthritis Rheum 40: 1725, 1997.

11) Bulkley BH, Roberts WC. The heart in systemic lupus erythematosus and the changes induced in it by corticosteroid therapy. A study of 36 necropsy patients. Am J Med 58: 243-264, 1975.

12) Cervera R, Font J, Para C, et al. Cardiac disease in systemic lupus erythematosus: prospective study of 70 patients. Ann Rheum Dis 51: 156-159, 1992.

13) Jouhikainen T, Pohjola-Sintonen $S$, Stephansson E. Lupus anticoagulant and cardiac manifestations in systemic lupus erythematosus. Lupus 3: 167-172, 1994.

14) Roldan CA, Shively BK, Crawford MH. An echocardiographic study of valvular heart disease associated with systemic lupus erythematosus. $\mathrm{N}$ Engl J Med 335: 1424-1430, 1996.

15) Brenner B, Blumenfeld Z, Markiewicz W, Reisner SA. Cardiac involvement in patients with primary antiphospholipid syndrome. J Am Coll Cardiol 18: 931-936, 1991.

16) Cervera $R$, Khamashta A, Font J, et al. High prevalence of significant 


\section{Mitral Regurgitation due to Antiphospholipid Syndrome}

heart valve lesions in patients with the primary antiphospholipid syndrome. Lupus 1: 43-47, 1991.

17) Galve E, Candell-Riera J, Pigrau C, Permanyer-Miralda G, Garcia-DelCastillo H, Soler-Soler J. Prevalence, morphologic types, and evolution of cardiac valvular disease in systemic lupus erythematosus. N Engl J Med 319: 817-823, 1988.

18) Cervera R, Khamashta MA, Font J, et al. Antiendothelial cell antibodies in patients with the antiphospholipid syndrome. Autoimmunity 11: 1-6, 1991.

19) Hasselaar P, Derksen RH, Blokzijl L, de Groot PG. Crossreactivity of antibodies directed against cardiolipin, DNA, endothelial cells and blood platelets. Thromb Haemost 63: 169-173, 1990.

20) Del Papa N, Guidali L, Spatola L, et al. Relationship between anti-phospholipid and anti-endothelial cell antibodies, III: $\beta_{2}$-glycoprotein I mediates the antibody binding to endothelial membranes and induces the expression of adhesion molecules. Clin Exp Rheumatol 13: 179-185, 1995.

21) Ziporen L, Goldberg I, Arad M, et al. Libman-Sacks endocarditis in the antiphospholipid syndrome: immunopathologic findings in deformed heart valves. Lupus 5: 196-205, 1996.

22) Shahian DM, Labib SB, Schneebaum AB. Etiology and management of chronic valve disease in antiphospholipid syndrome and systemic lupus erythematosus. J Card Surg 10: 133-139, 1995. 